\title{
Mechanism of the Donghekou landslide triggered by the 2008 Wenchuan earthquake revealed by discrete element modeling
}

\author{
R.-M. Yuan ${ }^{1,2}$, C.-L. Tang ${ }^{3}$, J.-C. $\mathrm{Hu}^{3}$, and X.-W. Xu${ }^{1}$ \\ ${ }^{1}$ Key Laboratory of Active Tectonics and Volcano, China Earthquake Administration, Beijing 100029, China \\ ${ }^{2}$ Institute of Geology, China Earthquake Administration, Beijing 100029, China \\ ${ }^{3}$ Department of Geosciences, National Taiwan University, Taipei 10617, Taiwan \\ Correspondence to: J.-C. Hu (jchu@ntu.edu.tw)
}

Received: 24 August 2013 - Published in Nat. Hazards Earth Syst. Sci. Discuss.: 23 December 2013

Revised: 5 March 2014 - Accepted: 27 March 2014 - Published: 21 May 2014

\begin{abstract}
The huge Donghekou landslide was triggered by the Wenchuan earthquake in 2008 with about $2.4 \times 10^{7} \mathrm{~m}^{3}$ of rock displaced. The landslide is considered as an example of an earthquake-induced "ejection" event, where dislocated slope materials was expelled over a section of the slope, but the kinematic processes are not well understood. We used the 2-D granular discrete element method to characterize the kinematic behavior and mechanics of this "ejection landslide". The initial boundary conditions were applied along the ball-wall contacts by using derived velocities integrated from strong motion data with a duration of $125 \mathrm{~s}$, including the peak acceleration near the Donghekou area. The constraints were primarily determined from the final geometry of the landslide and geological structures to account for the actual landslide characteristics. Simulated results showed that the large local seismic acceleration and a free face under the sliding body, caused by the dip difference between the upper slide face and the natural slope, originated from the activation of the landslide. For the lower sliding body, its kinematic mechanism was changed during sliding. Initially it was a push-type landslide, and then gradually changed to a retrogressive landslide. The eroded bed on the slope during the landslide had the potential of slightly increasing the runout distance from 1435 to $1519 \mathrm{~m}$, and was predicted in the numerical simulation.
\end{abstract}

\section{Introduction}

Earthquakes cause large-scale ground movement (shaking) and can trigger severe landslides over broad areas resulting in serious damage and casualties (Harp and Jibson., 1996; Central Geological Survey, 2000; Chigira et al., 2003; Keefer et al., 2006; Keefer and Larsen, 2007; Dai et al., 2010). To analyze an earthquake-induced landslide hazard, in addition to describing the regional correlation between seismic events and landslides under various conditions, it is critical to study the failure mechanism of catastrophic earthquake-induced landslides. However, the assessment of catastrophic landslides requires knowledge of landslide characteristics and runout mechanics.

The complex kinematics of the flowing mass depends on the morphological and geological characteristics of the slope, rheology of the surface material, and the triggering process. To better evaluate the failure mechanism within the moving mass and possible causes of the runout, both empirical and numerical models can be used. In general, empirical models lack robustness due to the comprehensive description of complex geological and geotechnical conditions of large flowlike landslides (e.g., Legros, 2002). However, a continuous method demonstrates the advantage of representing the complex geometry of a rock avalanche in this way (Crosta et al., 2006). Refined numerical solutions and a Coulomb-like behavior have been successfully derived for landslides (Iverson and Denlinger, 2001; Iverson and Vallance, 2001; Denlinger and Iverson, 2004), which often involve heterogeneous granular materials such as rocks and debris that may fall, topple or slide (Cruden and Varnes, 1996). For numerical models, 
many researchers have adopted discrete element methods to analyze landslides (Campbell et al., 1995; Poisel and Roth 2004; Poisel et al., 2005; Staron, 2007; Peng, 2008; Tang et al., 2009a, b, 2013). This research validated numerical modeling based on discrete element methods, which is a powerful tool for modeling rock slope failure due to seismic shaking.

After the Donghekou landslide triggered by the 2008 Wenchuan earthquake, several field investigations were carried out for landslide mapping and to define trigger mechanisms (Yin, 2008, 2009; Yin et al., 2009, 2011; Sun et al., 2009a, b; Wang et al., 2009; Tang et al., 2010; Yuan et al., 2010, 2013; Zhang et al., 2011; Huang and Fan, 2013). Meanwhile, numerical simulations based on various investigations were also applied to analyze the movement processes (Li et al., 2012; Zhang et al., 2012). However, the kinematic processes controlling the moving mass and the mechanism for some special phenomena associated with this huge landslide are still poorly understood because of the complicated movement processes and unique type.

In this paper, we try to address some special phenomena of the Donghekou landslide using the 2-D discrete element method for granular materials, which is helpful for characterizing the complex kinematics and triggering process of a large landslide. We focus especially on explaining the ejection of the upper landslide body and the formation of two disconnected landslide surfaces.

\section{The Donghekou landslide}

On 12 May 2008, the $\mathrm{Mw}=7.9$ Wenchuan earthquake struck the Longmenshan area, Sichuan Province, China, along the middle segment of the Longmenshan thrust belt, at the eastern margin of the Tibetan Plateau (Fig. 1a). Field investigations showed that the co-seismic surface rupture zones along the Beichuan-Yingxiu Fault and the Pengguan Fault propagated unilaterally in a northeast direction for over $300 \mathrm{~km}$, involving thrusting and right-lateral components ( $\mathrm{Xu}$ et al., 2009).

The Wenchuan earthquake triggered thousands of mass movements in the Longmenshan area (Dai et al., 2010), where some huge landslides caused an extreme loss of life and property (Yin, 2008). Among these landslides, the Donghekou landslide was exceptional, located at the northeast end of the Beichuan Rupture $\left(32.40572^{\circ} \mathrm{N}\right.$, $105.11081^{\circ} \mathrm{E}$ ), and caused serious loss of life at the village of Donghekou, Qinchuan, Sichuan Province (Fig. 1a, b). It can be described as the combination of two effects: the primary landslide and a significant rock fall. In this paper, only the primary landslide is simulated to better understand its formation mechanism.

The primary landslide, with an estimated volume of about $2.4 \times 10^{7} \mathrm{~m}^{3}$, originated at an elevation ranging between 1150 and $1350 \mathrm{~m}$; it traveled downhill towards the northeast for about $2.45 \mathrm{~km}$, and ended at the confluence of the

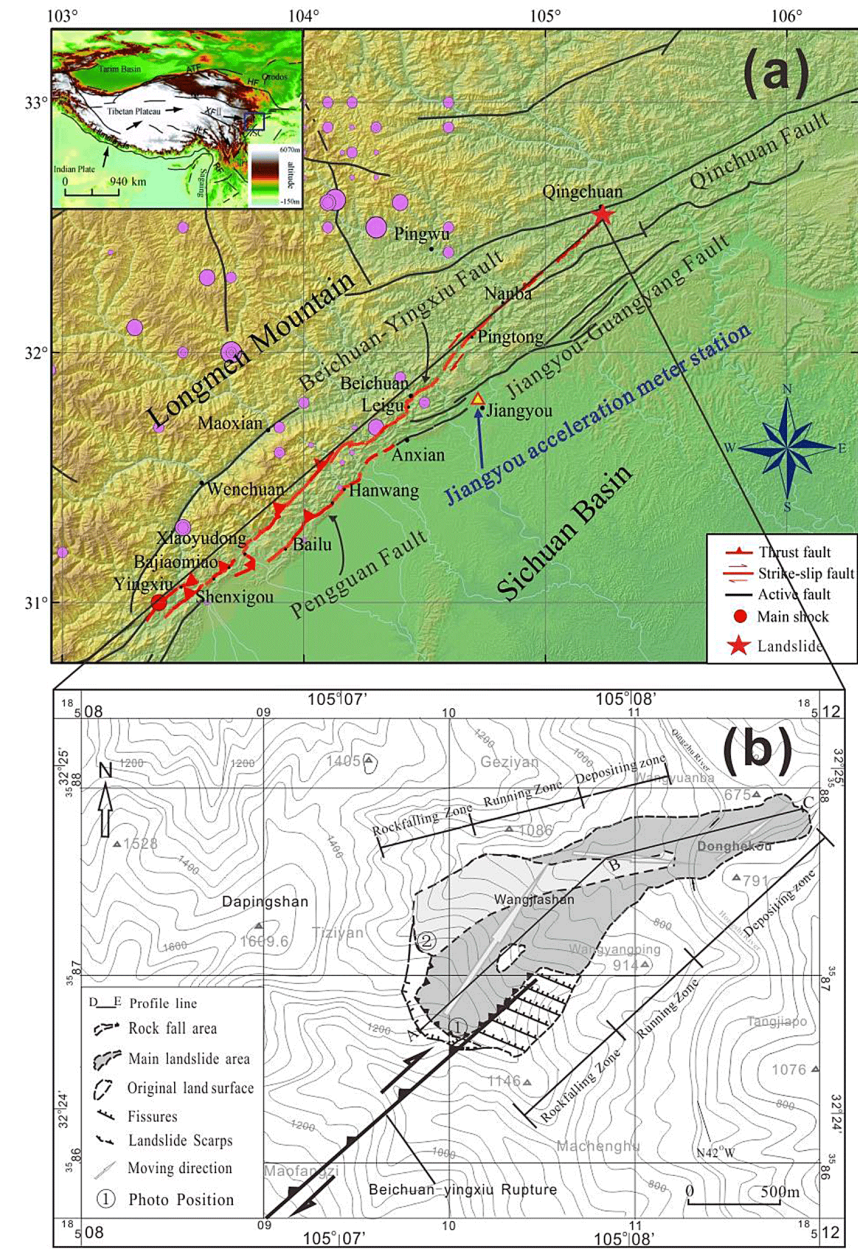

Figure 1. Main shock of the Wenchuan earthquake: regional structures (a), and outline of the Donghekou landslide (b).

Qingzhu and Hongshihe Rivers where two large lakes were formed. The vertical drop from the ridge to the rivers is approximately $600 \mathrm{~m}$ (Figs. $1 \mathrm{~b}$ and 2 ).

The field investigation along profile A-B-C (position shown in Fig. 1b) reveals that the sliding surface is neither continuous nor uniform. Instead, the surface can be divided into two parts (Fig. 2): the upper, very rough and deep sliding face, and the lower, very shallow sliding surface. The upper sliding body cuts through the mountain top with a quite rough and steep main scarp, and there is an area of undisturbed ground between the upper and lower sliding surface. Therefore, it was inferred that the landslide started with material mobilization due to the large local seismic acceleration, expelling rocks into the air on a parabolic trajectory before they fell back to the ground (Huang, 2009; Yuan et al., 2010; Xu and Dong 2011; Zhang et al., 2011). A simple tectonic geomorphology model was introduced to explain the movement characteristics of the landslide (Yuan et al., 2010; Tang et al., 2010), but its complex kinematics and triggering process still remain poorly understood. 


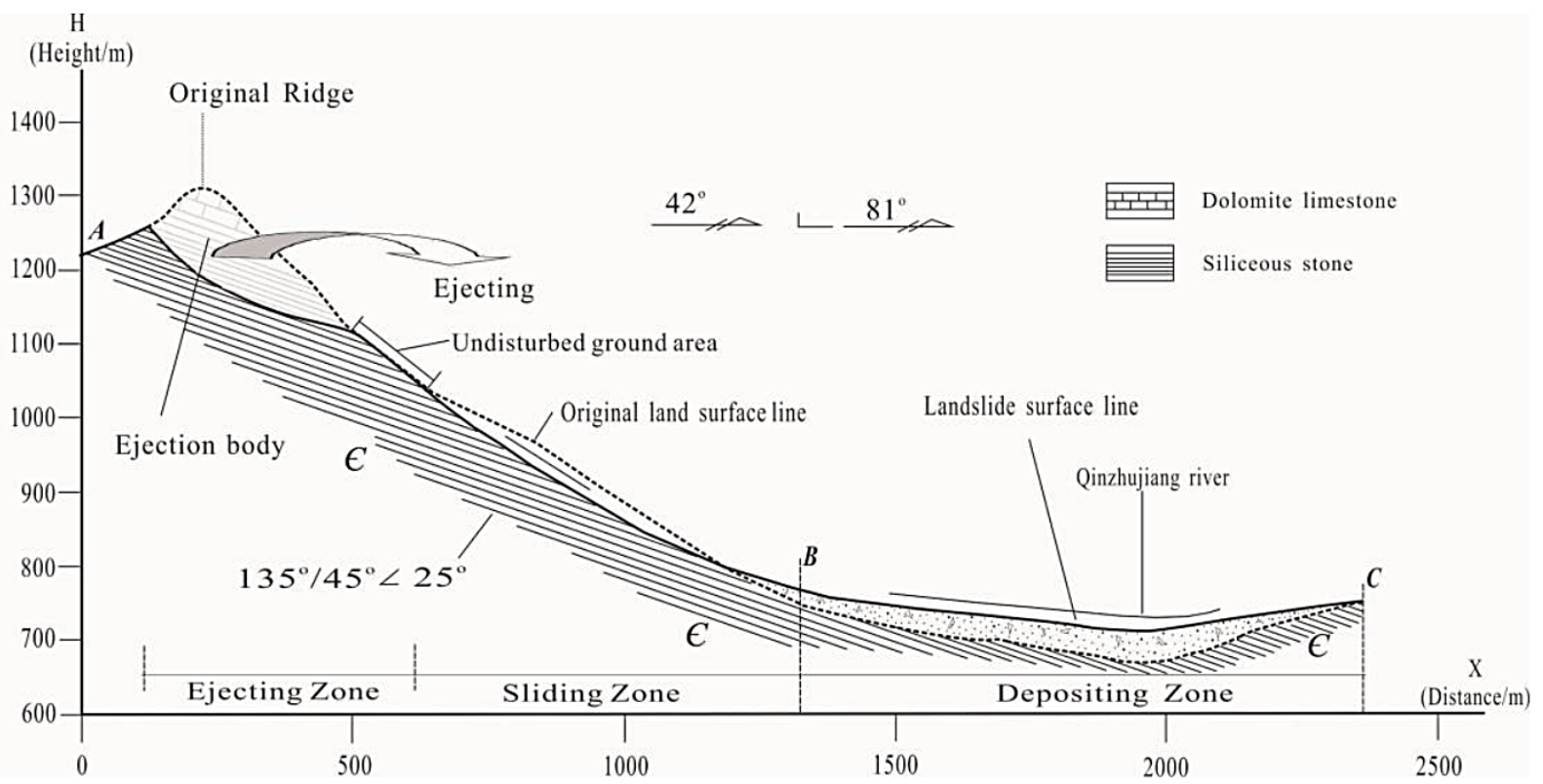

Figure 2. A geologic profile (A-B-C) of the Donghekou landslide (Yuan et al., 2010; profile shown in Fig. 1).

\section{Geological setting of the Donghekou area}

The Donghekou landslide is located in a mountainous region at the northern termination of the Beichuan rupture zone (Fig. 1). The elevation of the Dapingshan Mountain, where the Donghekou landslide occurred, is $1609.6 \mathrm{~m}$. Its slope is approximately uniform at $40^{\circ}$, though portions of the mountain surface are as steep as $70^{\circ}-80^{\circ}$. Such steep conditions are partly responsible for the occurrence of such a complex landslide.

The two main outcropping geological formations along the mountain slopes are dolomite limestone and siliceous phyllite. The dolomite limestone, with an orientation of $41^{\circ} \angle 26^{\circ}$, was observed mostly in the rock fall area, on the northwest side of the ejection landslide, and only a few limestone outcrops were found at the top of the slope (Fig. 2). In contrast, the siliceous phyllite, with an orientation of $41^{\circ} \angle 26^{\circ}$, was observed mainly in the area of the main landslide and in the zone of the domino-like ground tension fissures.

\section{The Newmark displacement method and two-dimensional distinct element modeling}

The Newmark displacement method and a discrete granular simulation technique were used in this paper to investigate the mechanics of the Donghekou landslide. The major methodological and technical aspects of the numerical simulation are summarized below.

\subsection{Principles of the Newmark displacement method}

In 1965, N. M. Newmark first proposed the basic elements of a procedure for evaluating potential deformations of an embankment dam due to earthquake shaking (Newmark, 1965). By computing the ground motion acceleration at which the inertial force becomes sufficiently high to cause yielding, as shown in Fig. 3, and integrating the acceleration exceeding the yield acceleration in the sliding mass, the ultimate displacement can be evaluated. Here the authors applied the Newmark displacement method to calculate the free-body force of the Donghekou landslide mass during the 2008 Wenchuan earthquake, assuming that the block slid when the peak acceleration was beyond the yield acceleration. The free-body diagram illustrates the situation of the sliding block before the earthquake (Fig. 3). Thus the force normal to the slope is $\operatorname{mg} \cos \delta$, where $m$ is the mass of the free-body, $g$ is the gravitational acceleration, and $\delta$ is the dip angle of the inclined surface. A basal friction force $\mu_{\mathrm{s}} m g \cos \delta$ consequently balances the $m g \sin \delta$ downslope force generated by gravity, so that the stability condition can be written as

$m g \sin \delta<\mu_{\mathrm{s}} m g \cos \delta+c A$,

where $\mu_{\mathrm{s}}$ is the coefficient of static friction, $c$ is the cohesive strength along the sliding surface, and $A$ is the area of the sliding surface.

We then introduced the safety factor, FS (Newmark, 1965; Wilson and Keefer, 1983), to evaluate the sliding threshold across an existing bedding plane:

$\mathrm{FS}=\left(\mu_{\mathrm{s}} m g \cos \delta+c A\right) /(m g \sin \delta)$. 


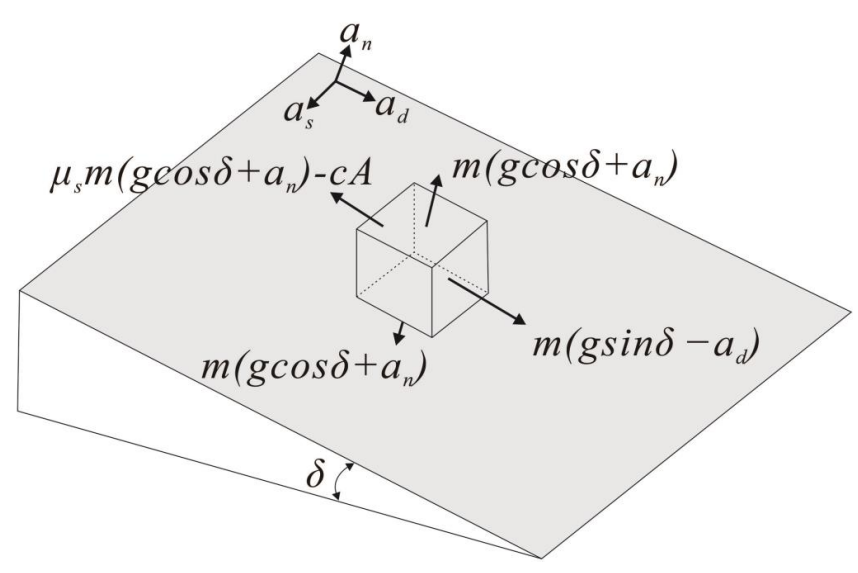

Figure 3. Diagram illustrating the critical balance condition of forces exerted on a rock block lying on an inclined planar surface under the earthquake ground motion.

For the Donghekou landslide, because the initial slide direction almost coincided with the dip of the underlying surface, the initial movement was inferred to be a nearly pure translation. We adopted the cohesion of intact shale of $1.65 \times 10^{4} \mathrm{~N} \mathrm{~m}^{-2}$ (Sun et al., 2009a), a density of $2.6 \mathrm{~g} \mathrm{~cm}^{-3}$ and a $\operatorname{dip} \delta=25^{\circ}$. The calculated FS was greater than 1 . We inferred that sliding over an existing bedding plane is only possible if other external triggering mechanisms are present (such as an earthquake or rainfall), or if the down-dip acceleration $a_{\mathrm{d}}$ is beyond the yield acceleration.

To calculate the down-dip sliding acceleration, $\mathrm{S}$, the data obtained from the nearest station measuring PGA (peak ground acceleration), situated in the Jiangyou valley at $\left(31.8^{\circ} \mathrm{N}, 104.7^{\circ} \mathrm{E}\right)$, was used to analyze the PGA values in the Donghekou area:

$\mathrm{S}=\left(g \sin \delta-a_{\mathrm{d}}\right)-\mu_{\mathrm{s}}\left(g \cos \delta+a_{\mathrm{n}}\right)-c A / m$,

where $a_{\mathrm{d}}$ and $a_{\mathrm{n}}$ refer to the down-dip and normal-to-sliding components of acceleration, respectively.

\subsection{Distinct element modeling}

The technique of distinct element modeling (DEM) was first developed to simulate rock-block systems (Cundall, 1971); it was later applied to the modeling of granular material (Cundall and Strack 1979). DEM is currently widely used in research related to rock mechanics and brittle tectonics (e.g., $\mathrm{Hu}$ and Angelier, 2004; Egholm, 2007; Egholm et al., 2007; Yang et al., 2014). The main calculation uses a time-explicit method and is capable of bonding particles into a mass by bonds. Particle Flow Code (PFC) models are made up of discrete particles, allowing for individual movements. The points where particles touch each other are called contacts. The numerical modeling technique that we adopted for the experiments reported here involved a particular application, PFC2D, of the 2-D particle flow code (Itasca, 2002). This technique is commonly used for modeling granular assemblages with purely frictional or bonded circular particles represented by discs and is now widely used to resolve rock engineering and geomechanics problems (e.g., Wang et al., 2003; Potyondy and Cundall, 2004; Tang et al., 2009a, b, 2013, 2014).

\subsubsection{Microproperties}

All numerical simulations by PFC modeling require proper selection of microparameters by means of calibration processes in which the response of the numerical modeling is compared with the observed results of the physical material. Attempts to improve and simplify the calibration process and modeling procedure have been reported in the literature (e.g., Itasca, 2002; Potyondy and Cundall, 2004). More recently, the application of experimental design and optimization in uniaxial compression simulations was proposed to calculate proper microparameters for model generation in PFC (Yoon, 2007). For a bond model, the overall mechanical behaviors of the assembly of particles are controlled by microproperties such as normal and shear stiffness, normal and shear bonds, and the Coulomb friction coefficient. There is no straightforward solution with regard to microproperties and macroproperties, but a relationship exists between the two scales of properties for an initial calibration.

Young's modulus of the material is linearly related to the value of contact stiffness. Parallel bonds increase contact stiffness (Itasca, 2002). Young's moduli of the grains $\left(E_{\mathrm{c}}\right)$ and cement $\left(E_{\mathrm{c}}\right)$ are expressed by

$$
\begin{aligned}
& E_{\mathrm{c}}= \begin{cases}\frac{k_{n}}{2 t} & , \text { PFC2D Disk mode } \\
\frac{k_{n}}{4 R} & , \text { PFC3D, PFC2D Sphere model }\end{cases} \\
& \overline{E_{\mathrm{c}}}=k^{P}\left(R^{(A)}+R^{(E)}\right),
\end{aligned}
$$

where $k_{\mathrm{n}}, K^{\mathrm{p}}, R$ and $t$ are normal particle stiffness, parallel bond normal stiffness, particle radius and disk thickness, respectively (Potyondy and Cundall, 2004). Thus, Poisson's ratio depends both on the ratio of shear contact stiffness to normal contact stiffness and packing geometry. The peak strength of the material depends both upon the friction coefficient and the bond strength (Itasca, 2002).

When using discrete element methods, the macroscopic behavior of the granular media depends on the contact mechanical microproperties. Because there is no straightforward method of linking microscopic and macroscopic parameters, a series of biaxial numerical tests were performed on granular samples to derive the mechanical macroproperties of the granular rock assembly. Because no complete theory can reliably predict macroscopic behavior from microscopic properties and geometry, the iterative trial-and-error processes in numerical biaxial tests were performed for the calibration of mechanical parameters. After parameter calibration, the microproperties were used for the 2-D particle assembly in PFC, and are listed in Table 1. 
Table 1. Microproperties and macroproperties of models based on a series of biaxial tests.

\begin{tabular}{|c|c|c|c|}
\hline \multicolumn{4}{|l|}{ Parameters of the packing of disks } \\
\hline Disk density & $2650\left(\mathrm{~kg} \mathrm{~m}^{-3}\right)$ & Parallel bond modulus (on slope) & $50 \mathrm{MPa}$ \\
\hline Disk thickness & $2(\mathrm{~m})$ & Ball friction coefficient & 0.5 \\
\hline Ball-ball contact modulus (on slope) & $50 \mathrm{MPa}$ & Parallel bond normal strength non-parallel to strata (landslide block) & $10 \mathrm{MPa}$ \\
\hline Ball stiffness ratio & 1 & Parallel bond shear strength parallel to strata (landslide block) & $50 \mathrm{MPa}$ \\
\hline Minimum ball radius (Rmin) & $0.64 \mathrm{~m}$ & Parallel bond shear strength non-parallel to strata (landslide block) & $10 \mathrm{MPa}$ \\
\hline
\end{tabular}

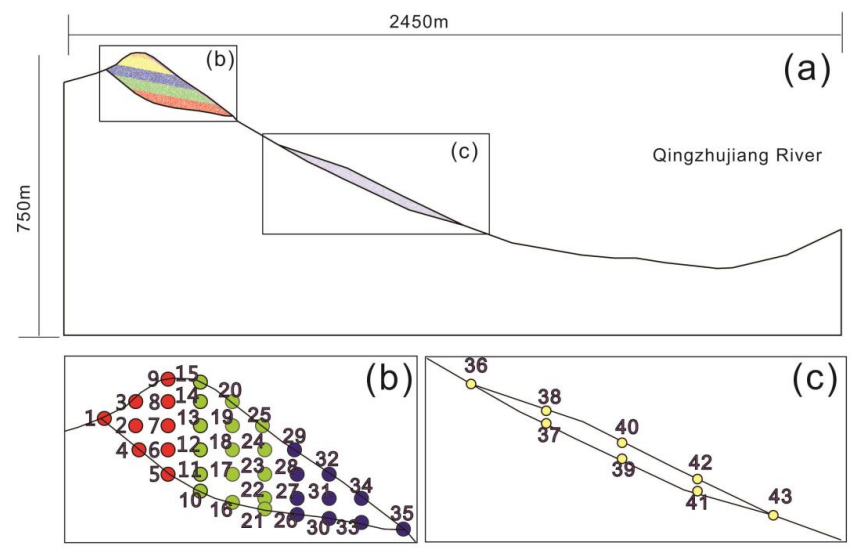

Figure 4. Numerical model of the Donghekou landslide and the monitoring disks within the sliding blocks.

\subsubsection{Numerical model for the Donghekou landslide}

The dimensions employed in the Donghekou landslide model were $2450 \mathrm{~m}$ (length) and $750 \mathrm{~m}$ (height) (Fig. 2). A profile of the slope was first built to perform a numerical simulation. In the numerical model, the rocks under the sliding surface were represented by "wall elements". Then, the particles composing the sliding mass were randomly generated inside the entire deforming region, including the upper sliding body and lower sliding mass (Fig. 4a). The different colors in the upper sliding body show the process of the destruction of the sliding body, and do not indicate different materials. To illustrate the velocity and displacement during sliding, some monitoring disks were installed within the upper and lower sliding blocks, as shown in Fig. $4 \mathrm{~b}$ and c. The monitoring disks for the upper ejection body were chosen at different heights from the lower to the upper part. For the lower sliding body, the monitoring disks were chosen based upon the sliding face and ground surface.

The mechanical and geometrical properties of the elements are evaluated according to geological considerations. Based on in situ observations in the landslide area, the adopted disk diameter ranged from 1.28 to $2.56 \mathrm{~m}$ with a uniform distribution. Using these choices, the total number of
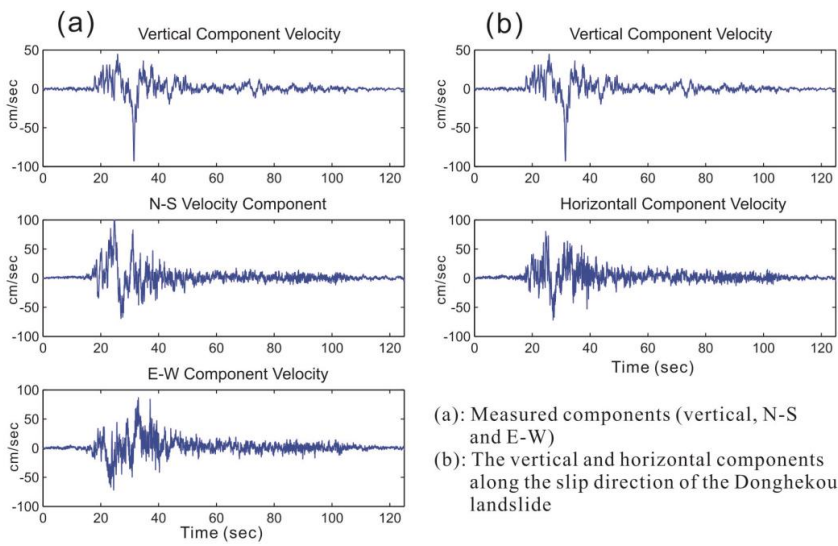

(a): Measured components (vertical, $\mathrm{N}-\mathrm{S}$ and $\mathrm{E}-\mathrm{W}$ )

(b): The vertical and horizontal components along the slip direction of the Donghekou landslide

Figure 5. Velocity diagram of the accelerometer station in Jiangyou during the Wenchuan earthquake.

particles was 10000 for the upper and 5000 for the lower sliding bodies respectively. The interparticle coefficient of friction was set at 0.5 , which was determined from the residual friction coefficient of joints in the rock mass (Table 1). Strong motion vibration was applied to the model boundary by integrating the acceleration of the seismic station in the Jiangyou valley that recorded the Wenchuan earthquake (Fig. 5a). Based on the data from this station and the scalingup of the topography effect in this area suggested by Wang et al. (2009), the vertical and horizontal components along the slip direction of the Donghekou landslide were calculated (Fig. 5b).

In our series of experiments, we adopted variable values for two major parameters of the numerical experiments: the residual friction coefficient at the landslide surface and the internal bonding strength parameters. In the present paper, the residual friction coefficient ranged from 0.05 to 0.3 , and two different values (50 and $10 \mathrm{MPa}$ ) were used for parallel bond strength. All the parameters used in the simulation are listed in Table 1. 


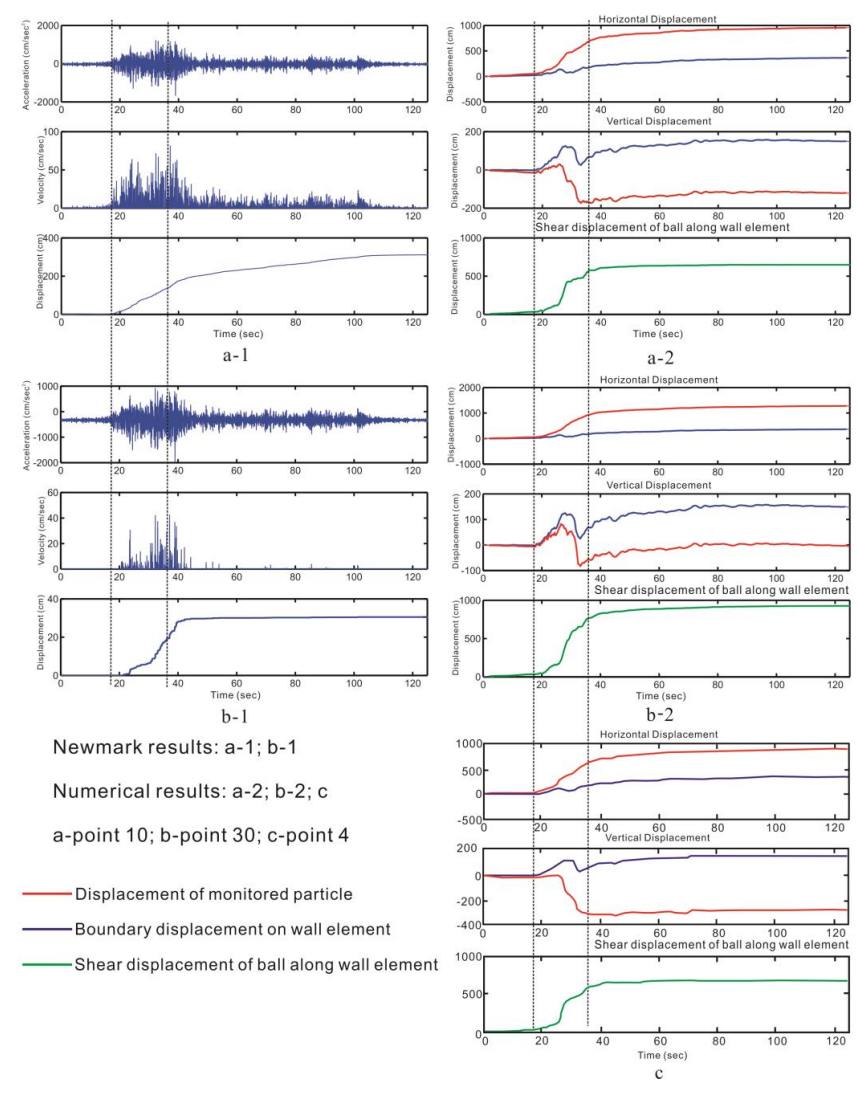

Figure 6. Acceleration and displacement under shaking based on Newmark and numerical methods. (The red and blue lines in the right column of Fig. 6 are the displacements of the monitored particles and boundary displacements, respectively. Positions of the disks are shown in Fig. 4.)

\section{Results and analysis}

During calculation and modeling, particular attention was devoted to displacement amplitudes and the sliding process, to analyze the failure mechanism and formation processes of the two separate landslide bodies of the Donghekou landslide.

\subsection{Displacement amplitudes}

The displacement and down-dip sliding acceleration of monitoring disks during the vibrations were calculated and simulated during the shaking process. We used the Newmark displacement method to analyze the acceleration of the Jiangyou station (see also Fig. 5). By integrating the effective acceleration on the sliding mass in excess of this yield acceleration as a function of time, velocities and ultimately displacements of the sliding mass were evaluated.

The calculations were based on three points with different local slopes, respectively, including points 4, 10 and 30 (Fig. 4); the friction coefficient was set at 0.5. When the acceleration reached the peak value, sliding was trig- gered. Point 4 was unstable, because the local slope was $39^{\circ}\left(\tan 39^{\circ}>0.5\right)$, allowing the rock mass to slide without earthquake action. For points 10 and 30, the calculations showed that several different acceleration peaks existed beyond the yield acceleration (Fig. 6). Obvious deformation of slide block occurred at about $17 \mathrm{~s}$ and the landslide yielded thoroughly at about $35 \mathrm{~s}$. After calculating the final integration of the peaks, we found a total sliding value between block and sliding surface, as determined by the Newmark displacement method, of about $311 \mathrm{~cm}$ for point 10 (Fig. 6a-1) and about $31 \mathrm{~cm}$ for point 30 (Fig. 6b-1).

If the influence of pore or fissure water on the landslide was not accounted for, the disks then only slid by no more than $311 \mathrm{~cm}$ for point 10 and $31 \mathrm{~cm}$ for point 30 during the Wenchuan earthquake, prior to the catastrophic event. The possible mechanisms of the Donghekou landslide will be discussed based on discrete particle simulations. At this stage, we show only the simulation results for these three points for comparison with the calculated results.

For the Donghekou landslide, the simulated displacements of disks 10,30 and 4 during the seismic shaking process were calculated using a coefficient of friction of 0.5 (Fig. 6a-2, b-2, c). In our simulation results, obvious deformation of the sliding block also occurred at about $17 \mathrm{~s}$, and the landslide also yielded completely at about $35 \mathrm{~s}$, which agreed with the values obtained from the Newmark displacement method. However, for the simulated displacements, the disks slid by no more than $672 \mathrm{~cm}$ for point $10,926 \mathrm{~cm}$ for point 30 and $648 \mathrm{~cm}$ for point 4 during the Wenchuan earthquake; these figures obviously do not agree with the values obtained from the Newmark displacement analysis. After the vibration simulation, the discordant shear displacement on the landslide detachment plane was observed. These gaps could be explained by the effect of the interaction of particles included in the simulation method, such as collision between different disks (Tang et al., 2013). The upper part of the block moved backwards when it collided the lower part of the block. Hence, the displacement of the monitored point 30 is larger than that of monitored particles 4 and 10. In the Newmark method, only the movement of a single disk was calculated.

\subsection{Sliding process}

Because PFC2D uses an explicit solution scheme that gives stable solutions to unstable processes, it describes and accurately locates the nonlinear behavior observed in the Donghekou landslide. Simulated results at different time steps can therefore be shown and described. The simulated results are shown in Fig. 7 and indicate that in the initial stage, the deformation only occurred in the upper sliding mass. Then, the upper sliding face was formed at about $35 \mathrm{~s}$ when the sliding body began to move down to gouge out the upper sliding base (Fig. 7b). Following that, the sliding body then collided with the ground at about $55 \mathrm{~s}$, causing the 
Table 2. Runout distance of the monitoring disks in the landslide blocks.

\begin{tabular}{lllllllll}
\hline & $\begin{array}{l}\text { Disk } \\
\text { no. }\end{array}$ & $\begin{array}{l}\text { Runout } \\
\text { distance, } \\
\mathrm{m}\end{array}$ & $\begin{array}{l}\text { Disk } \\
\text { no. }\end{array}$ & $\begin{array}{l}\text { Runout } \\
\text { distance, } \\
\mathrm{m}\end{array}$ & $\begin{array}{l}\text { Disk } \\
\text { no. }\end{array}$ & $\begin{array}{l}\text { Runout } \\
\text { distance, } \\
\mathrm{m}\end{array}$ & $\begin{array}{l}\text { Disk } \\
\text { no. }\end{array}$ & $\begin{array}{l}\text { Runout } \\
\text { distance, } \\
\mathrm{m}\end{array}$ \\
\hline Upper disks & 3 & 1079 & 21 & 1730 & 32 & 1802 & 40 & 1358 \\
Lower disks & 4 & 1263 & 22 & 1304 & 30 & 1548 & 39 & 1069 \\
\hline
\end{tabular}
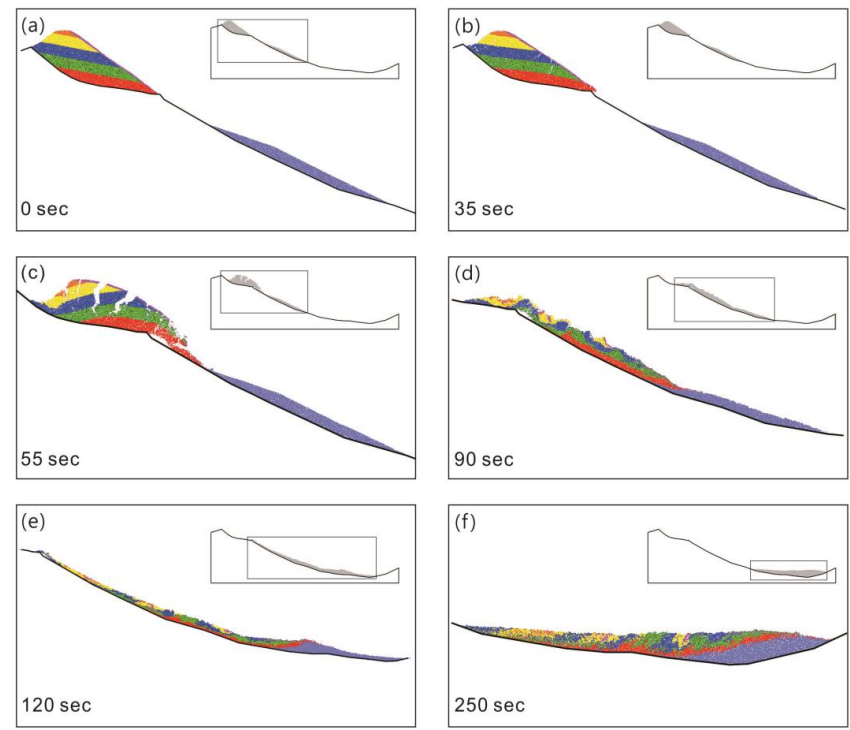

Figure 7. Simulated results of the Donghekou landslide at different time stages.

lower sliding mass to slide (Fig. 7c). At $90 \mathrm{~s}$, the lower sliding face was formed; the lower sliding mass also began to move down because of its weight and the impact of the upper sliding body (Fig. 7d). Thereafter, the landslide arrived at the Qinzhujiang River at 120 s (Fig. 7e). In the final stage, the Qinzhujiang and Hongshihe rivers were cut off by the deposits of the landslide, forming two lakes (Fig. 7f).

\subsection{Runout distance}

To illustrate the runout distances, some monitoring disks were incorporated into the sliding blocks (Fig. 4b, c). Every monitoring disk is assigned a number to identify the position change. Different colors are also used for the disks in different segments of the sliding block to facilitate discussion of deformation in the upper sliding block (Fig. 4).

For the upper and lower sliding blocks, the initial lengths are about $300 \mathrm{~m}$ from monitoring disks 1 through 35, and about $500 \mathrm{~m}$ from monitoring disks 36 through 43, respectively. The entire length of the deposit area is about $1200 \mathrm{~m}$. During sliding, the disks in the downslope area collided with the disks in the rear which underwent acceleration in the downslope direction. The runout distances of disks from

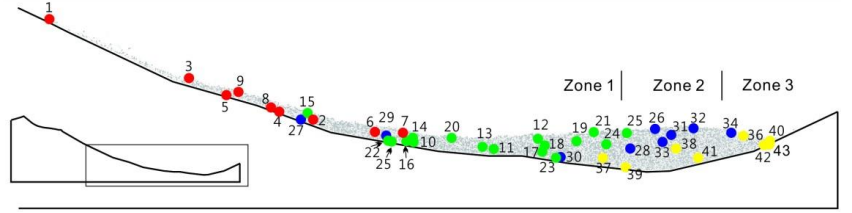

Figure 8. Final positions of monitoring disks after landslide.

the upper layers generally have longer runout distances than those from the deeper layers (Fig. 8, Table 2). The disks in the lower sliding block formed a disordered pattern because of collision or being collided by the upper slide block. Disk 36 in this block has a longer runout distance of about $1650 \mathrm{~m}$, which is larger than that of disk 40. However, for the upper sliding body, the relative locations of different disk groups with different colors remain largely unchanged, although the positions of disks in the same color zone are disturbed, and some blocks may change in depth inside the sliding mass (such as disks 22, 25, 31 and 32) (Fig. 8). According to Fig. 8, the deposition area can be divided roughly into three zones, including zone 1 with materials mainly from the upper sliding body, zone 2 with mixed materials from both sliding bodies and zone 3 with materials mainly from the lower sliding body. No obvious boundary exists between different zones. This simulated result is consistent with the field investigation results. In Fig. 9, point a is the position of the upper sliding body, point $\mathrm{b}$ is the position of undisturbed ground area, and point $\mathrm{c}$ is the position of the lower sliding body. The upper sliding body is mainly composed of grey-black siliceous phyllite and the lower is composed mainly of yellow unconsolidated sediments. Based on colors of materials, the deposition area in Fig. 9 can be divided into zones 1,2 and 3 .

\section{4 "Ejection" phenomenon}

The simulated results show that the upper sliding face was formed at about $35 \mathrm{~s}$ (Fig. 7b) and then the upper sliding body began to move down to gouge out the upper sliding base. When the upper sliding body separated from the upper segment sliding face, a free face was formed under the sliding block because of the different dip angles between the upper sliding face and the surface slope. In this stage, some obvious cracks were developing and began to split the sliding body (Fig. 10a). The upper sliding body was then ejected into 


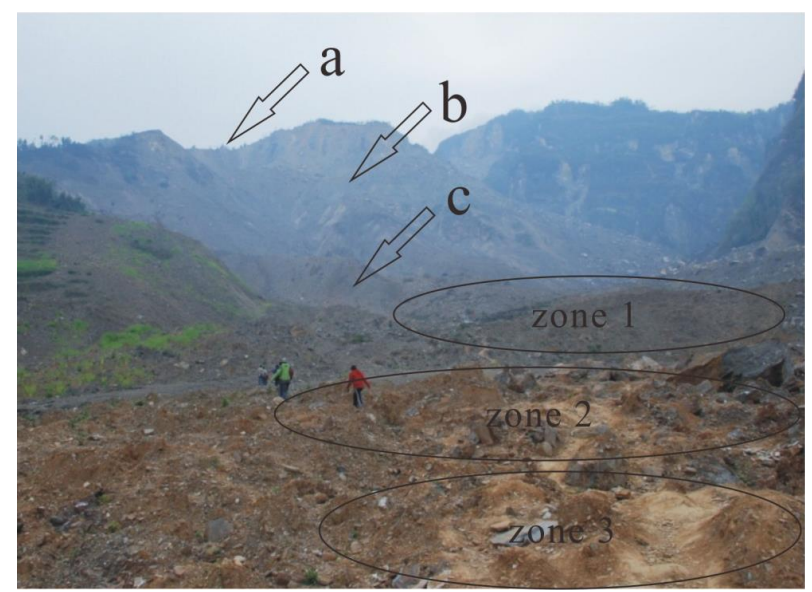

Figure 9. Zone division of landslide deposits based on material colors (view looking to the southwest).

the air at high velocity. At the same time, the sliding body was destroyed because it developed more cracks (Fig. 10b). Because the ejected body flew through the air, portions of the original ground surface and vegetation remained undisturbed around the zone of ejection; field investigations confirmed the presence of undisturbed ground under the upper sliding body (point $b$ in Fig. 9). When falling back to earth, the ejected body disintegrated into debris. At the same time, it began to collide the lower sliding body, pushing it downwards (Fig. 10c).

\subsection{Mechanism of the lower sliding body}

When the ejected body fell back to earth to collide and push down the lower sliding body at about $55 \mathrm{~s}$, the formation of the lower segment of the sliding face was initiated. Although different sections of the lower sliding body have different velocities, we compare only the displacements of the rear and front parts of the lower sliding body. This is sufficient for describing the sliding mechanism of the lower sliding body. Displacement changes at different locations are shown in Fig. 10. The time intervals were chosen based on the simulation results to illustrate the change of sliding type.

According to Fig. 10, from 55 to $65 \mathrm{~s}$, a $10 \mathrm{~m}$ displacement occurred at the rear part of the lower sliding body. However, no displacement occurred at the toe part of the slide indicating that the lower sliding body began to be moved by the falling upper sliding body. The continuous sliding face was not formed at this stage. However, the displacement at the toe of the slide, which is smaller than that at the rear, occurred between 65 and $75 \mathrm{~s}$. The sliding face then probably became continuous and the sliding block moved down along the sliding face. At this stage, the lower landslide became a push-type landslide. From 75 to $85 \mathrm{~s}$, the whole lower sliding bodies moved down with the same velocity. Afterwards, the landslide changed to the retrogressive type, because the
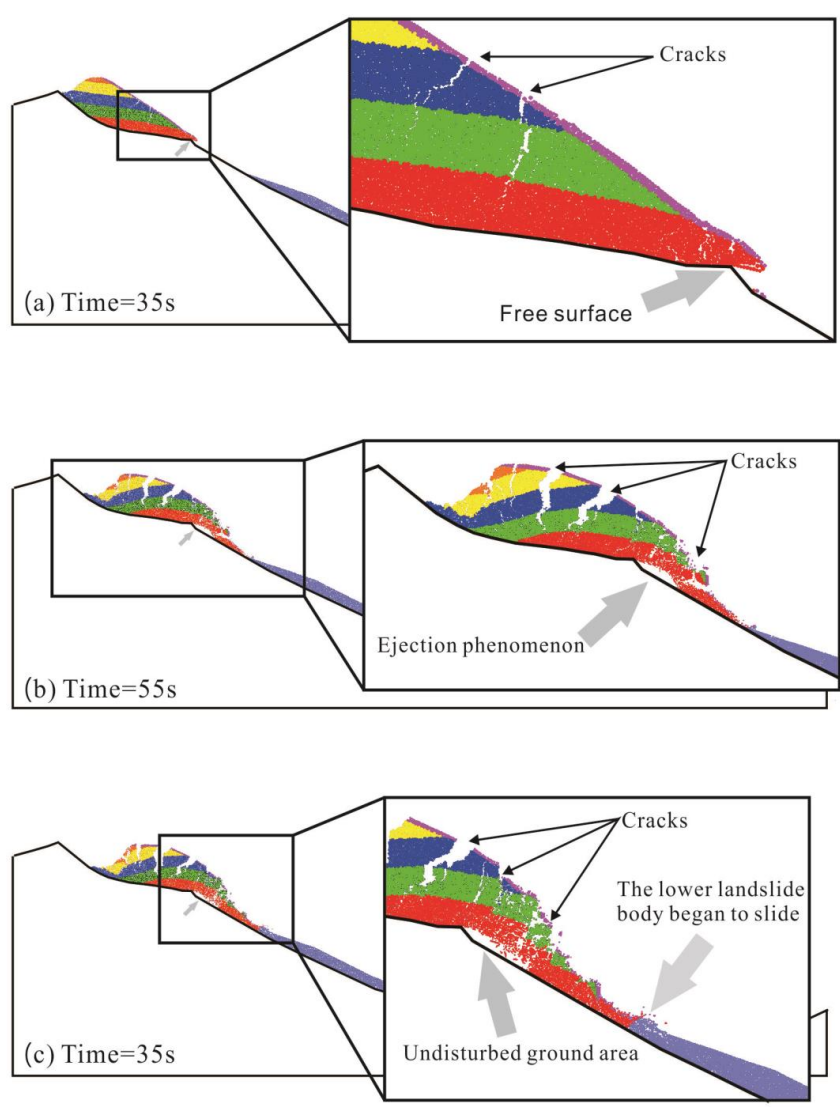

Figure 10. "Ejection" phenomenon in the Donghekou landslide.

displacement of the toe part was larger than that of the rear part of the landslide. The state between 85 and 95 s (Fig. 11) shows this change.

\subsection{Role of erosion processes}

Erosion processes also strongly affect the kinematic and runout distances of granular flow on moderate slopes, as shown by Mangeney et al. (2007, 2010). They pointed out that the erosion of granular material already present on the bed built up by earlier events can significantly increase (by up to $40 \%$ ) the mobility of avalanches flowing on moderate slopes (Mangeney et al., 2010). In the case of the Donghekou landslide, the influence of eroded beds was only highlighted in the destruction of the original ground surface (Figs. 2 and $4 \mathrm{c}$ ), which added eroded material to the landslide as it hurtled down (Fig. 11). We ran two numerical models, in which the basal erosion model was reproduced based on the model in Fig. 4a. The erosion bed, which was destroyed and slid down when the landslide occurred, is marked in blue (Fig. 12).The non-basal erosion model kept this blue part intact, and the landslide material flowed over it (Fig. 12). In the non-basal erosion model, the runout was $1435 \mathrm{~m}$ and in the basal erosion model, the runout increased to $1519 \mathrm{~m}$ with 


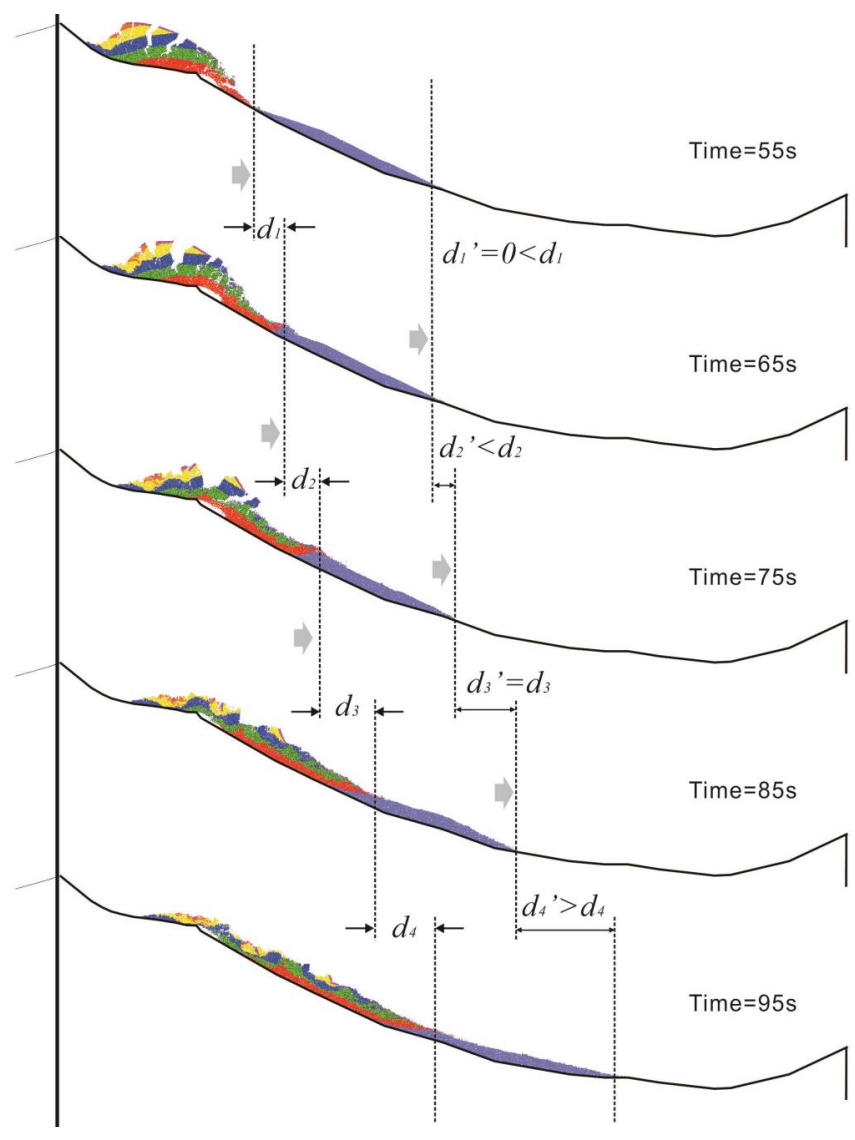

Figure 11. Displacement changes in different parts of the lower landslide body.

the additional contribution caused by the destruction of the eroded beds.

\section{Conclusions}

Based on field studies of the 2008 Donghekou landslide, numerical modeling was conducted to better understand the ejection phenomenon and the formation mechanism of two different sliding faces. The simulated results showed that the large local seismic acceleration and a free face under the sliding body caused by the dip difference between the upper sliding face and the natural slope are responsible for the "ejection" phenomenon of the landslide. For the lower sliding body, its kinematic mechanism was changed during sliding; it was initially a push-type landslide and then changed to a retrogressive landslide. We conclude that the seismic shaking initiated the sliding in the upper part, and rock mass was expelled over some distance under the conditions of the specific geometry and sliding surface predicted in our numerical simulation.

This case study indicates that numerical modeling has the potential to bring tight constraints on landslide behavior, using information based on available observations and mea-

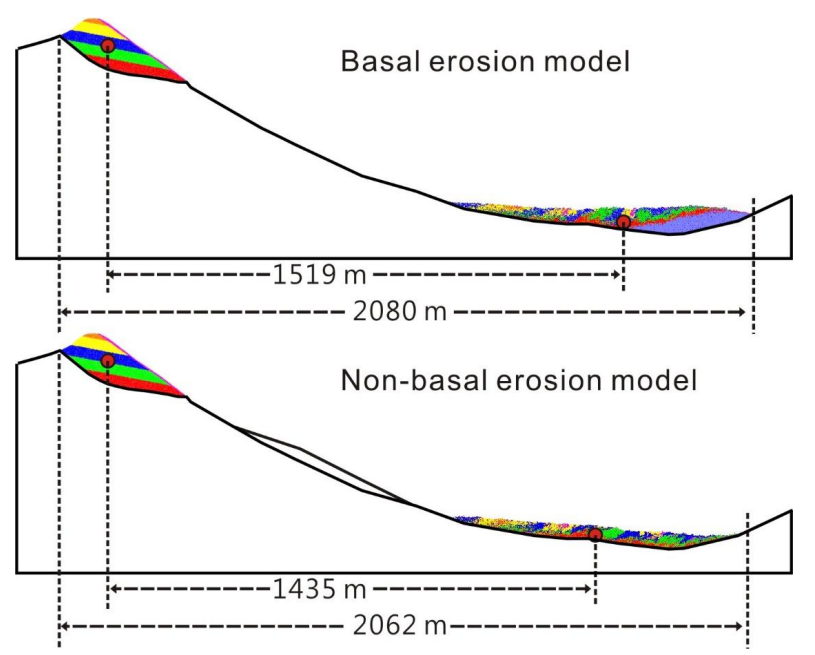

Figure 12. Runout of basal erosion model and non-basal erosion model.

surements, such as geological and geomorphological conditions, rock mechanics and so on. Two-dimensional modeling based on field observations could well explain the kinematic processes of the Donghekou landslide. However, to better explain the geometry of the motion and the lateral spreading of landslide materials, three-dimensional modeling should be undertaken in future to better define the features of landslide debris deposits.

Acknowledgements. We greatly appreciate the suggestions and comments from the Editor Andreas Günther and the two reviewers Hans-Balder Havenith and Xinpo Li, who helped to greatly improve the manuscript. We also thank Pei-Ling Wang for commenting on the figures. This study was supported in part by the National Science Council under the grants NSC 97-2116-M-002-022-, 99-2116-M-002-005- and 100-2116-M-002-004-. This study was also supported by Natural Science Foundation of China projects (41172193) and Basic Scientific Funding of the Institute of Geology, China Earthquake Administration (IGCEA-1107).

Edited by: A. Günther

Reviewed by: H.-B. Havenith and X. Li

\section{References}

Campbell, C. S., Cleary, P. W., and Hopkins, M.: Large-Scale landslide simulations: global deformation velocities and basal friction, J. Geophys. Res., 100, 8267-8283, 1995.

Central Geological Survey (Republic of China): Landslide disasters of Taiwan. Geohazard Report, Central Geological Survey, MOEA, Taiwan, Taipei, 2000.

Chigira, M., Wang, W., Furuya, T., and Kamai, T.: Geological causes and geomorphological precursors of the Tsaoling landslide triggered by the 1999 Chi-Chi Earthquake, Taiwan, Eng. Geol., 68, 259-273, 2003. 
Crosta, G.B., Imposimato, S., and Roddeman, D.G.: Continuum numerical modeling of flow-like landlisdes. in: Landslide form massive rock slope failure, edited by: Evans, S. G., Mugnozza, G. S., Strom, A., and Hermanns, R. L., Netherlands, Springer, Earth Environ. Sci., 49, 211-232, 2006.

Cruden, D. M. and Varnes, D. J.: Landslide types and processes, in: Landslides Investigation and Mitigation, edited by: Turner, A. K. and Schuster, R. L., National Research Council, Transportation Research Board, Washington DC, 36-75, 1996.

Cundall, P. A.: A computer model for simulating progressive large scale movement in blocky rock systems, Proc. Sym. Int. Soc. Rock. Mech., Nancy France 1, II-8, October, 1971.

Cundall, P. A. and Strack, P. D. L.: A discrete numerical model for granular assemblies, Geotechnique, 29, 47-65, 1979.

Dai, F. C., Xu, C., Yao, X., Xu, L., Tu, X. B., and Gong, Q. M.: Spatial distribution of landslides triggered by the $2008 \mathrm{Ms} 8.0$ Wenchuan earthquake, China, J. Asian. Earth Sci., 40, 883-895, 2010.

Denlinger, R. P. and Iverson, R. M.: Granular avalanches across irregular three-dimensional terrain: 1 . Theory and computation, Geophys. Res., 109, F01014, doi:10.1029/2003JF000085, 2004.

Egholm, D. L.: A new strategy for discrete element numerical models: 1. Theory, J. Geophys. Res., 112, B05203, doi:10.1029/2006JB004557, 2007.

Egholm, D. L., Sandiford, M., Clausen, O. R., and Nielsen, S. B.: A new strategy for discrete element numerical models: 2. Sandbox applications, J. Geophys. Res., 112, B05204, doi:10.1029/2006JB004558, 2007.

Harp, E. L. and Jibson, R. W.: Landslides triggered by the 1994 Northridge, California earthquake, Bull. Seismol. Soc. Amer., 86, s319-s332, 1996.

Hu, J.-C. and Angelier, J.: Stress permutations: Three-dimensional distinct element analysis accounts for a common phenomenon in brittle tectonics, J. Geophys. Res., 109, B09403, doi:10.1029/2003JB002616, 2004.

Huang, R. and Fan, X.: The landslide story, Nature Geosci. 6, 325326, 2013.

Huang, R. Q.: Mechanism and geomechanical models of landslide hazards triggered by Wenchuan 8.0 Earthquake, Chinese J. Rock Mech. Eng., 28, 1239-1249, 2009.

Itasca, Consulting Group Inc. PFC2D Particle Flow Code in 2 Dimensions, User's Guide, Minneapolis, 2002.

Iverson, R. M. and Denlinger, R. P.: Flow of variably fluidized granular masses across three-dimensional terrain. 1. Coulomb mixture theory, J. Geophys. Res., 106, 537-552, 2001.

Iverson, R. M. and Vallance, J. W.: New views of granular mass flows, Geology, 29, 115-118, 2001

Keefer, D. K. and Larsen, M. C.: Assessing landslide hazards, Science, 316, 1136-1138, 2007.

Keefer, D. K., Wartman, J., Navarro-Ochoa, C., Rodriguez-Marek, A., and Wieczorek, G. F.: Landslides caused by the M 7.6 Tecomán, Mexico earthquake of January 21, 2003, Eng. Geol., 86, 183-197, 2006.

Legros, F.: The mobility of long-runout landslides, Eng. Geol., 63, 301-331, 2002.

Li, X., He, S., Lou, Y., and Wu, Y.: Simulation of the sliding process of Donghekou landslide triggered by the Wenchuan earthquake using a distinct element method, Environ, Earth Sci., 65, 10491054, 2012.
Mangeney, A., Tsimring, L. S., Volfson, D., Aranson, I. S., and Bouchut, F.: Avalanche mobility induced by the presence of an erodible bed and associated entrainment, Geophys. Res. Lett., 34, L22401, doi:10.1029/2007GL031348, 2007.

Mangeney, A., Roche, O., Hungr, O., Mangold, N., Faccanoni, G., and Lucas, A.: Erosion and mobility in granular collapse over sloping beds, J. Geophys. Res.-Earth Surface, 115, F03040, doi:10.1029/2009JF001462, 2010.

Newmark, N. M.: Effect of earthquake on dams and embankments, Geotechnique 15, 139-160, 1965.

Peng, J. H.: A study on sliding process and depositing behavior in Chiufengershan Landslide, Mater Thesis, National Taiwan University, Taipei, 2008.

Poisel, R. and Roth, W.: Runout models of rock slope failures, Felsbau, 22, 46-50, 2004.

Poisel, R., Bendarik, M., Holzer, R., and Liščák, P.: Geomechanics of hazardous landslides, J. Mt. Sci., 2, 211-217, 2005.

Potyondy, D. O., and Cundall, P. A .: A bonded-particle model for rock, Int. J. Rock Mech. Min. Sci., 41, 1239-1364, 2004.

Sun, P., Yin, Y.P., and Wu, S. R.: Experimental study on shear strength of rocks from Donghekou Landslide in dried state and saturated state, Geol. Bull. China, 28, 1163-1167, 2009a.

Staron, L.: Mobility of long-runout rock flows: a discrete numerical investigation, Geophys. J. Int., 172, 455-463, 2007.

Sun, P., Zhang, Y. S., and Yin, Y. P.: Discussion on long runout sliding mechanism of Donghekou landslide-debris flow, J. Eng. Geol., 17, 737-744, 2009b.

Tang, C.-L., Hu, J.-C., Lo, C.-M., and Lin, M.-L.: The catastrophic 1999 Tsaoling and 2009 Hsiaoling klandslides: Preliminary study from 3-D distinct element modeling, Sino-Geotec, 122, 143-152, 2009a (in Chinese).

Tang, C.-L., Hu, J.-C., Lin, M.-L., Angelier, J., Lu, C.-Y., Chan, Y.C., and Chu, H.-T.: The Tsaoling landslide triggered by the ChiChi earthquake, Taiwan: Insights form a discrete element simulation, Eng. Geol., 106, 1-19, 2009 b.

Tang, C.-L., Hu, J.-C., Lin, M.-L., Yuan, R. M., and Cheng, C.-C.: The mechanism of the 1941 Tsaoling landslide, Taiwan: Insight from a 2D discrete element simulation, Environ. Earth Sci., 70, 1005-1019, 2013

Tang, H., Jia, H., Hu, X., Li, D., and Xiong, C.: Characteristics of landslide induced by the great Wenchuan earthquake, J. Earth Sci., 21, 104-113, 2010.

Wang, C., Tannant, D. D., and Lilly, P. A.: Numerical analysis of the stability of heavily jointed rock slopes using PFC2D, Int. J. Rock Mech. Min. Sci., 40, 415-424, 2003.

Wang, Y. S., Xu, H. B., Luo, Y. H., and Wu, J. F.: Study of formation conditions and toss motion program of high landslides induced by earthquake, Chinese J. Rock Mech. Eng., 28, 23602368, 2009 (in Chinese).

Wilson, R. C. and Keefer, D. K.: Dynamics analysis of a slope failure from the 6 August 1979 Coyote Lake, California, Earthquake, Bull. Seismol. Soc. Amer., 65, 1239-1257, 1983.

$\mathrm{Xu}, \mathrm{Q}$. and Dong, X. J.: Genetic types of large-scale landslides induced by Wenchuan Earthquake, Earth Sci. J. China Univ. Geosci., 36, 1134-1142, 2011.

Xu, X. W., Wen, X., Yu, G., Chen, G. H., Klinger, Y., Hubbard, J., and Shaw, J.: Coseismic reverse- and oblique-slip surface faulting generated by the $2008 \mathrm{Mw} 7.9$ Wenchuan earthquake, China, Geology, 37, 515-518, 2009. 
Yang, Y.-R., Hu, J.-C., and Lin, M.-L.: Evolution of coseismic faultrelated folds induced by the Chi-Chi earthquake: A case study of the Wufeng site, Central Taiwan by using 2D distinct element modeling. J. Asian Earth Sci., 79, 130-143, 2014.

Yin, Y.: Researches on the Geohazards triggered by Wenchuan earthquake, Sichuan, J. Eng. Geol., 16, 1-12, 2008 (in Chinese).

Yin, Y.: Features of landslides triggered by the Wenchuan Earthquake, J. Eng. Geol., 17, 29-38, 2009 (in Chinese).

Yin, Y., Wang, F., and Sun, P.: Landslide hazards triggered by the 2008 Wenchuan earthquake, Sichuan, China, Landslides, 6, 139152, 2009.

Yin, Y., Zheng, W.,Li, X., Sun, P., and Li, B.: Catastrophic landslides associated with the M8.0 Wenchuan earthquake, Bull. Eng. Geol. Environ., 70, 15-32, 2011.

Yoon, J.: Application of experimental design and optimization to PFC model calibration in uniaxial compression simulation, Int. J. Rock Mech. Min. Sci., 44, 871-889, 2007.
Yuan, R. M., Xu, X. W., Chen, G. H., Tan, X. B., Klinger, Y., and Xing, H. L.: Ejection landslide at northern terminus of Beichuan rupture triggered by $2008 \mathrm{Mw} 7.9$ Wenchuan earthquake, Bull. Seismol. Soc. Amer., 100, 2689-2699, 2010.

Yuan, R. M., Deng, Q. H., Cunningham, D., Xu, C., Xu, X. W., Chen, G. H., and Chang, C. P.: Density distribution of landslides triggered by the 2008 Wenchan earthquake and their relationships to peak ground acceleration, Bull. Seismol. Soc. Amer., 103, 2344-2355, 2013.

Zhang, L. M., Xu, Y., Huang, R. Q., and Chang, D. S.: Particle flow and segregation in a giant landslide event triggered by the 2008 Wenchuan earthquake, Sichuan, China, Nat. Hazards Earth. Syst. Sci., 11, 1153-1162, 2011.

Zhang, Y., Chen, G., Wu, J., Zheng, L., and Zhuang, X.: Numerical simulation of seismic slope stability analysis based on tensionshear failure mechanism, Geotech. Eng. J. SEAGS \& AGSSEA, 43, 18-28, 2012. 